\title{
DESIGN AND OPTIMIZATION OF FRONT AXLE OF HEAVY TRUCK
}

\author{
Mr. Khot S.S. \\ PG Student, Department of Mechanical Engineering \\ DVVPCOE Ahmednagar, Maharashtra, India
}

\begin{abstract}
The shaft may be a central shaft for a rotating wheel. On wheeled vehicles, the shaft is also fastened to the wheels, rotating with them, or fastened to its surroundings, with the wheels rotating round the shaft. The axles serve to transmit driving torsion to the wheel, yet on maintain the position of the wheels relative to every different and to the vehicle body. The axles in an exceedingly system should conjointly bear the load of the vehicle and any load. The front shaft beam is one in all the most important components of car mechanical system. It homes the steering assembly yet. Regarding thirty five to 40percent of the overall vehicle weight is obsessed by the front shaft.
\end{abstract}

Hence correct style of the front shaft beam is very crucial. In gift analysis work style of the front shaft of significant industrial vehicle were done. The approach during this project has been divided into 2 steps. Within the start, front shaft was designed in Solid Work code later the model is foreign into ANSYS for results. Within the second step, the model is allotted with 2 completely different materials and therefore the analysis results for each the materials square measure compared to conclude an acceptable material for a Front shaft producing.

\section{Index Terms - Axle, Solid Work Software, ANSYS}

\section{INTRODUCTION}

\section{FRONT AXLE AND STEERING SYSTEM}

Front shaft carries the burden of the front a part of the car likewise as facilitates steering and absorbs shocks because of paved surface variations. The front axles square measure typically dead axles, however square measure live axles in little cars of compact styles and conjointly just in case of machine drive. The mechanism converts the motility of the driver's handwheel into the angular turning of the front wheels likewise on multiply the driver's effort with leverage or mechanical advantage for turning the wheels. The steering system, in addition to directing the vehicle in a particular direction must be arranged geometrically in such a way so that the wheels undergo true rolling motion without slipping or scuffing. Moreover, the steering should be lightweight and stable with a particular degree of self-adjusting ability. Steering systems may also be power assisted. The chapter discusses the front

\author{
Prof. Dr.Navthar R.R. \\ Dean \& Professor Department of Mechanical Engineering \\ DVVPCOE Ahmednagar, Maharashtra, India
}

shaft construction and its align-ment, and steering pure mathematics and steering systems.

\section{FRONT AXLE}

The front shaft is meant to transmit the burden of the car from the springs to the front wheels, turning right or left as needed. To prevent interference because of front engine location, and for providing larger stability and safety at high speeds by lowering the centre of gravity of the road vehicles, the entire centre portion of the axle is dropped. As shown in Fig, front axle includes the axle-beam, stub-axles with brake assemblies, truck-rod and stub-axle arm.

Front axles can be live axles and dead axles. A live front axle contains the differential mechanism through which the engine power flows towards the front wheels. In the axle of the half shaft constant velocity joints are fixed for steering the fornt wheels. Without moving the ability flow through the 0.5 shafts, these joints help in turning the stub axles around the king-pin. The front axles square measure typically dead axles, which does not transmit power. The front wheel hubs rotate on antifriction bearings of tapered-roller kind on the steering spindles, that square measure Associate in Nursing integral a part of steering knuckles. To permit the wheels to be turned by the gear mechanism, the steering spindle and steering knuckle assemblies square measure hinged on the top of shaft. The pin that forms the pivot of this hinge is known as king pin or steering knuckle pin. Generally dead front axles are three types. In the Elliot kind front axles the yoke for king spindle is found on the ends of I-beam. The axle ends are forked to hold the steering knuckle extension between them. The reverse Elliot front axles have hinged spindle yoke on spindle itself rather than on the axle. The steering knuckle and forked portion are integrated. This type is often used as this facilitates the mounting of brake backing plate on the cast legs of the steering knuckle. In the Lemoine type front axle, instead of a yoke type hinge, an L-shaped spindle is used which is attached to the end of the axle by means of a pivot. It is normally used in tractors.

The shaft beam in use is of I or H-section and is factorymade from alloy cast steel for rigidity and strength. For live front axle different swivelling mechanisam is used to that of dead front axle. To connect the wheel hub axles with axle shafts, constant velocity joints are used for the vehicles fitted with the front live axles. Tracta, Rzeppa (or Sheppa) on Bendix constant speed or universal joints square measure commonly used. 


\section{International Journal of Engineering Applied Sciences and Technology, 2019 \\ Vol. 4, Issue 4, ISSN No. 2455-2143, Pages 183-191 \\ Published Online August 2019 in IJEAST (http://www.ijeast.com)}

Front axles square measure subjected to each bending and shear stresses. The axle is considered as beam supported vertically and loaded vertically upwards at the centre of the spring pads. The vertical bending moment thus caused is zero at the point of support and rises linearly to a maximum at the point of loading and then remains constant.

\section{LITERATURE SURVEY}

MinZhang, XiangfeiJi, LijunLi in there paper [1] did research on fatigue life of front axle beam for heavy-duty truck. Front shaft is one in all the necessary elements of auto. The Fatigue Tool in ANSYS Workbench software is used to analyze its strength situations and fatigue life. The dangerous space of beam is decided, which provides a certain basis for structure improvement. In addition, in view of three kinds of working condition often used, a combined fatigue simulation of multi working conditions is carried out. The influence of different conditions on fatigue life is studied. Finally, fatigue lifetime of front shaft containing crack is investigated to research the impact of crack parameters like length and depth on fatigue life. Zhen Li, Muneshi Mitsuoka , Eiji Inoue , Takashi Okayasu, Yasumaru Hirai [2] Developed stability indicators for dynamic Phase I overturn of conventional farm tractors with front axle pivot. Tractor overturns are serious potential hazards for operators. While change protecting structures (ROPS) shield operators passively, greater protection can be achieved through theoretical prediction of a potential overturn. When tyres lose the contact with ground the operator can correct the tractors motion with effective warning. Such a loss of contact is related to the initiation of a clinical test tractor overturn. However, it remains unclear how the initiation of tractor overturn is influenced by certain factors. The extension is required in mathematical model of the tractor for utilization.This study was conducted to develop stability indicators supported a additional general model for dynamic clinical test tractor overturn. We thought of sensible tractor configurations and motion characteristics during a 3 dimensional (3D) organisation in formulating the mathematical model. The force calculation gives the tractor stability indicators for overturn and sideslip. A constant study was conducted exploitation Associate in Nursing example tractor. The tractor speed and slope angle were found to have an effect on the overturning stability considerably. The constant of most static friction was found to be the most issue causative to tractor sideslip. Ketan Vijay Dhande1, Prashant Ulhe [3] has design and analysis of front axle of heavy commercial vehicle. torque to the wheel, additionally on maintain the position of the wheels relative to every alternative and to the vehicle body. The axles during a system should additionally bear the burden of the vehicle and any wares. The front shaft beam is one in all the main elements of auto mechanical system. It houses the steering assembly as well. About thirty five to forty p.c of the whole vehicle weight is obsessed by the front shaft. Hence correct style of the front shaft beam is extraordinarily crucial. In present research work design of the front axle for Ashok Leyland 1612 Comet heavy commercial vehicle were done. The approach in this project has been divided into two steps. In the opening front shaft was style by analytical methodology. TO find the stresses and defelction in the beam the specifications like payload capacity and gross weight is used. Pravin R.Ahire, Prof.K. H. Munde [4] has Design and analysis of front axle for heavy commercial vehicle. Front axle carries the weight of front part of the Automobile, as well as facilitates steering and absorbs shocks due to road surface variations. The front axle is designed to transmit the weight of the Automobile front the spring to the front wheels, turning right and left as required. So proper design of front axle beam is extremely crucial. The paper deals with design and analysis of front axle. The same analysis with help of FE results were compared with analytical design. For which paper has been divided in to two steps. In the first step front axle was design by analytical method. For this vehicle specification - its gross weight, payload capacity, braking torque used for subject to matter to find the principle stresses \& deflection in the beam has been used. In the second step front axle were modelled in CAD software \& analysis in ANSYS software. K.Padma Raju, B.Jithendra Kumar [5] has Design and Analysis of a Heavy Vehicle Front Axle. An shaft may be a central shaft for a rotating wheel. On wheeled vehicles, the axle may be fixed to the wheels, rotating with them, or fixed to its surroundings, with the wheels rotating around the axle. The axles serve to transmit driving torsion to the wheel, as well as to maintain the position of the wheels relative to each other and to the vehicle body. The axles should be able ot bear the vehicle weight and any other cargo. In the major parts of vehicle suspension system front axle beam plays important role. It houses the steering assembly as well. About thirty five to 40percent of the whole vehicle weight is obsessed by the front shaft. This leads proper design of front axle beam. In gift analysis work style of the front shaft of significant industrial vehicle were done. The approach in this project has been divided into two steps. In the first step, front axle was designed in CATIA V5 software later the model is imported into ANSYS for results. In the second step, the model is assigned with two different materials and the analysis results for both the materials are compared to conclude a suitable material for a Front axle manufacturing. S. Eswaran ,B.Dinakaran ,L.Jeevankumar ,K.P.Karthick , S.Karthick [6] has style and Structural Analysis Of serious Duty Vehicle Front shaft. Weight reduction plays a very important role in automobile parts. once the load of the vehicle is reduced then the fuel consumption of the actual vehicle are remittent. If the fuel consumption rate is magnified then the emission rate additionally will increase. the subsequent factors that largely affects the emission from the engine includes 


\section{International Journal of Engineering Applied Sciences and Technology, 2019 \\ Vol. 4, Issue 4, ISSN No. 2455-2143, Pages 183-191 \\ Published Online August 2019 in IJEAST (http://www.ijeast.com)}

vehicle category, weight, driving cycle, vehicle vocation, fuel sort and vehicle age. thanks to this the researchers have given additional importance for turn out lightweight weight parts. This analysis tries to cut back the load of the front shaft of an important duty vehicle. M.Porus Purushothaman, V Jayachandran [7] did the finite part analysis of front shaft frame of serious duty truck With CI material model. gift offhighway vehicle market demands low value and light-weight weight part to satisfy the necessity of value effective vehicle with fuel economical. This successively offers the increase to simpler use of materials for vehicle components which might scale back the weight with increased utility of car for varied applications. Weight reduction and ease in style square measure application of business engineering etc., the sources of the technique that square measure used. Stress analysis of front shaft of truck mix beneath static loading conditions resulted from the applied modifications was performed by victimization finite part technique. The business finite part package ANSYS version nine.0 was used for the answer of the matter. The front shaft needs a properly designed support with high strength and stiffness.

\section{PROBLEM STATEMENT}

Our vehicles are full of reciprocating, rotating parts that have to fall within certain measurements, or tolerances, in order to perform properly. If an axle gets bent which is actually quite easy to do in a collision or other mishap -- it will create a jostle of a ride afterward. With this problem, the vibrating often picks up in intensity the faster you drive. A related problem would be that the driveshaft also needs inspection. This rapidly spinning part transfer's engine power to the rear axles and wheels in rear-wheel drive vehicles. If it's bent, shaking may result. This leads requirement of non resonant and good fatigue life axle design. To improve life along with optimum design by varying its dimensions and material, need to investigate this study by doing finite element analysis.

\section{METHODOLOGY}

In this project the stress distribution will be evaluated on the Light duty truck engine front axle by using FEA. The finite element analysis is performed by using FEA software. The Modal analysis will be performed to calculate natural frequency. Static analysis due to Laden Weight $=6000 \mathrm{~kg}$ will be carried out to calculate stresses and deflection followed by fatigue analysis to calculate life axle. Three different materials will be studied here as below;

1. Structural Steel

2. Aluminum Alloy

3. Grey Cast iron
The best among above will be recommended for manufacturing. In this project the finite element analysis will be performed with using software ANSYS and CAD modeling will be done in SOLID WORKS.

The methodology used for doing the analysis is as follows:

- Develop a 3D model using SOLID WORKS software

- The 3D model is converted into .stp and imported into ANSYS.

- Performed Modal, Static and Fatigue analysis in ANSYS.

- Plot deflections, stresses and life for all material used in FEA.

- Proposed best material which has less mass and higher FOS.

- Performed bending test on actual part and correlate experimental results with FEA for validation.

IV.I. Calculation of weight

For TATA Light Truck

Laden Weight $=5970 \mathrm{~kg}$.

Actual weight coming on axle is,

Considering $3 \mathrm{~g}$ condition (bump load) $=3 * 5970=17910$ $\mathrm{Kg}$

Total Weight on axle is given by $=17910 * 9.81=175.69$ $\mathrm{kN}$

Weight on each spring seat $=175.69 / 2$

$$
=87.845 \mathrm{KN}
$$

\section{TOOL USED:}

Here Ansys 16.0 is used for analyzing natural frequencies and static deflection of beam. Front Axle is modeled in SOLID WORKS and it is imported in Ansys 16.0.

\section{GEOMETRY MODELING:}

CAD Modeling of any project is one in every of the foremost time overwhelming method. One cannot shoot directly from the shape sketches to Finite part Model. CAD (Geometry) modeling is that the base of any project. Finite part computer code can think about shapes, no matter is created in CAD model. CAD modeling of the front shaft style is performed by mistreatment SOLID WORKS and difeaturing in Ansys style modeler computer code.

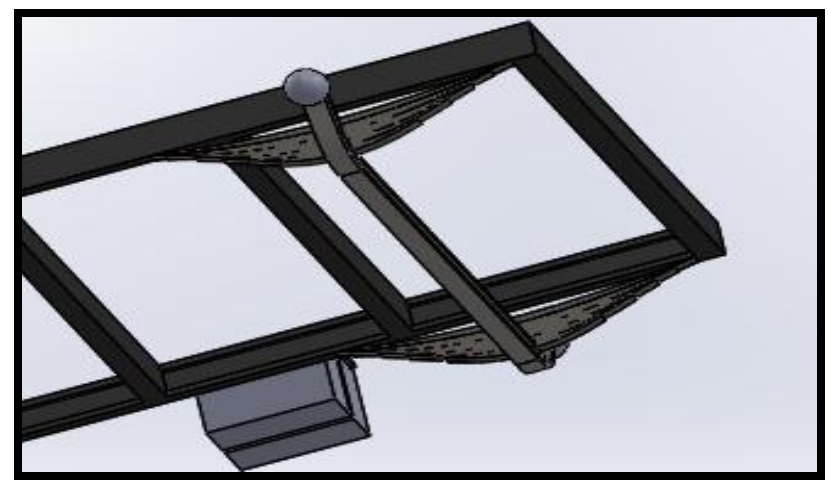

Fig: 1 CAD Model looking from Bottom 


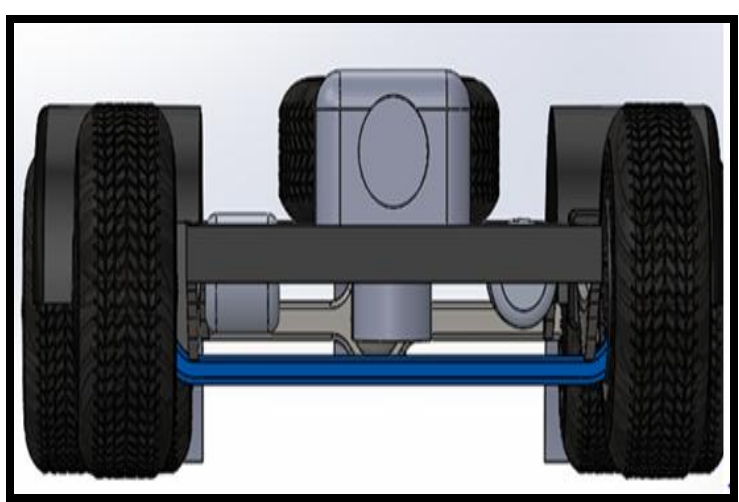

Fig: 2 CAD Model looking from Front

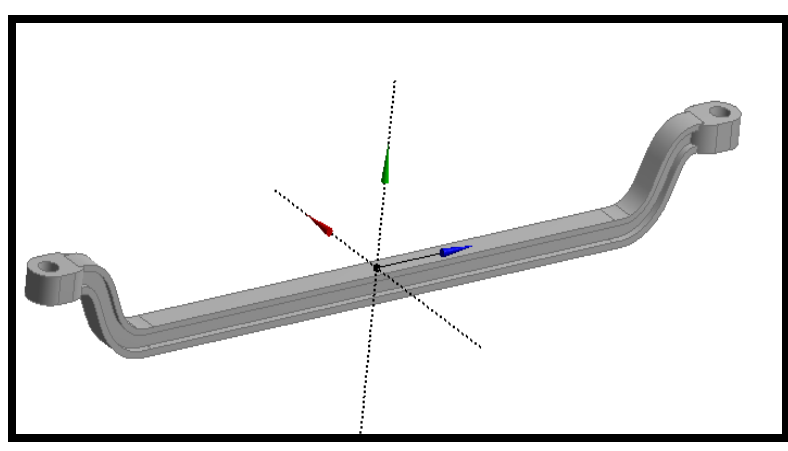

Fig:3 Front Axle used for analysis.

\section{MATERIAL PROPERTIES:}

- The displacement varies linerally, not parabolically which is known to us by checking midside node. We can refer Quadratic Elements (Midside Nodes) in the Modeling and Meshing Guide for information about using midside nodes.

- The mideside nodes can't be missed when we use mixed formulation is used $(\operatorname{KEYOPT}(6)=1$ or 2$)$

- If you use the mixed formulation $(\operatorname{KEYOPT}(6)=1$ or 2$)$, the damped eigen solver is not supported. You must use the sparse solver (default).

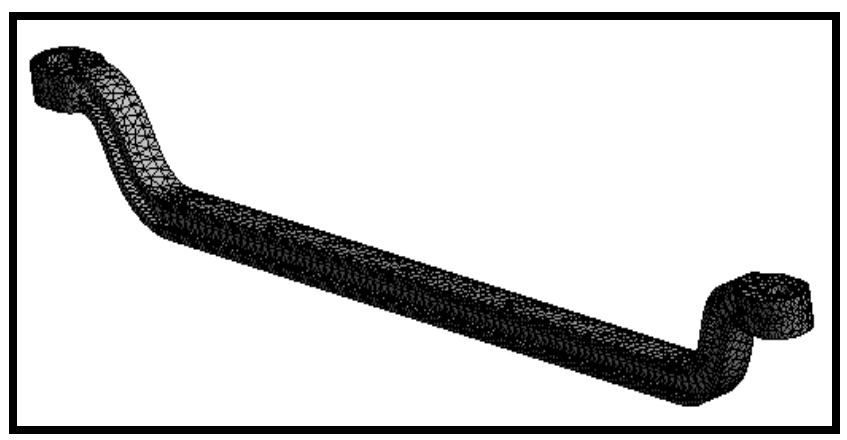

Fig 4: FE Modeling details; Nodes: 30009, Elements: 30009

\begin{tabular}{|c|c|c|c|}
\hline Material & $\begin{array}{c}\text { Young's } \\
\text { Modulus (GPa) }\end{array}$ & $\begin{array}{c}\text { Poisons } \\
\text { Ratio }\end{array}$ & $\begin{array}{c}\text { Density } \\
(\mathrm{Kg} / \mathrm{m} 3)\end{array}$ \\
\hline Steel & 200 & 0.3 & 7850 \\
\hline CI & 110 & 0.28 & 7200 \\
\hline $\begin{array}{c}\text { AL } \\
\text { Alloy }\end{array}$ & 71 & 0.33 & 2700 \\
\hline
\end{tabular}

Table No 1 Material Properties

\begin{tabular}{|c|c|c|c|}
\hline & \multicolumn{3}{|c|}{ Material Strength (MPA) } \\
\hline Material & $\begin{array}{c}\text { Yield } \\
\text { Strength }\end{array}$ & $\begin{array}{c}\text { Ultimate Tensile } \\
\text { Strength }\end{array}$ & $\begin{array}{c}\text { Ultimate Compressive } \\
\text { Stress }\end{array}$ \\
\hline Steel & 250 & 250 & 460 \\
\hline CI & 240 & 240 & 820 \\
\hline AL Alloy & 280 & 280 & 310 \\
\hline
\end{tabular}

Table No 2: Material properties

\section{STATIC ANALYSIS}

A static structural anal determine the displacement, stresses, strain, and Force in structures caused by loads that do not induced significant inertia and damping effect.

LOADS AND BOUNDARY CONDITIONS:

- $\quad$ End hole were constrained with fixed support and force based on design calculation were applied on leaf spring mounting location. Below figure shows the boundary condition for that for the front axle

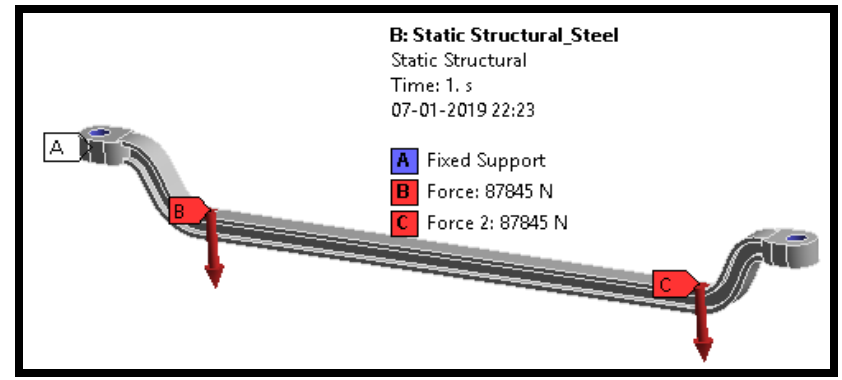

Fig.5 boundary condition for that for the front axle

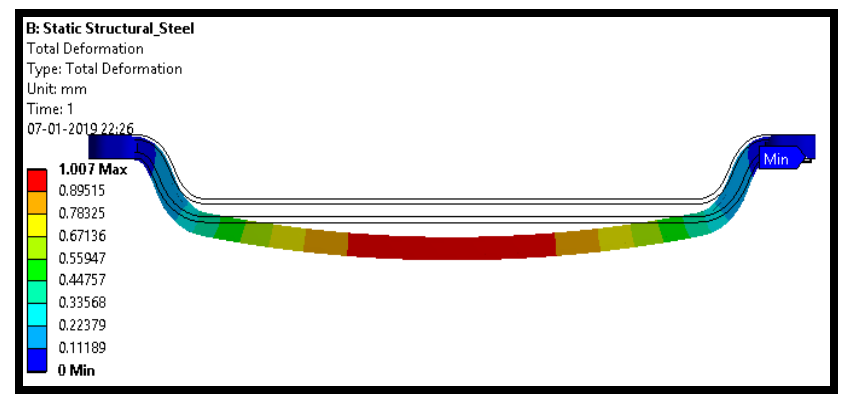

Fig:6 Structural Steel Deformations

When we check the Deformation of the structural steel under the loading condition at that time it structural steel deformed by $1.007 \mathrm{~mm}$. 
Fig:9 Von Mises Stress Plot of Steel

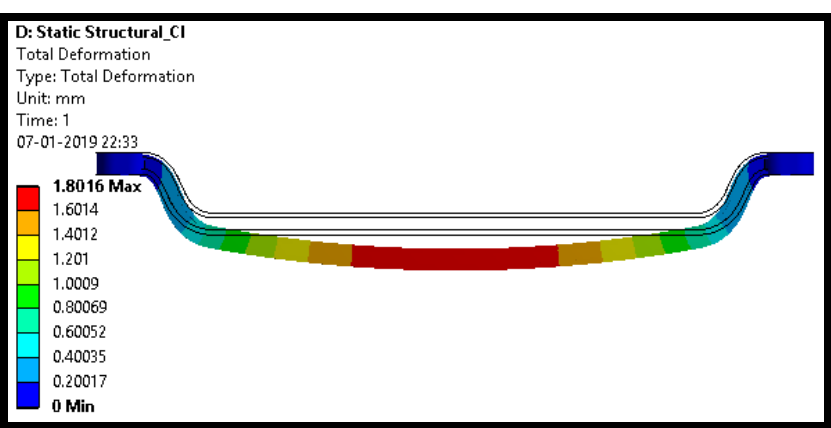

Fig:7 Gray Cast Iron Deformation

When we check the Deformation of the Gray cast iron under the loading condition at that time it structural steel deformed by $1.8016 \mathrm{~mm}$.

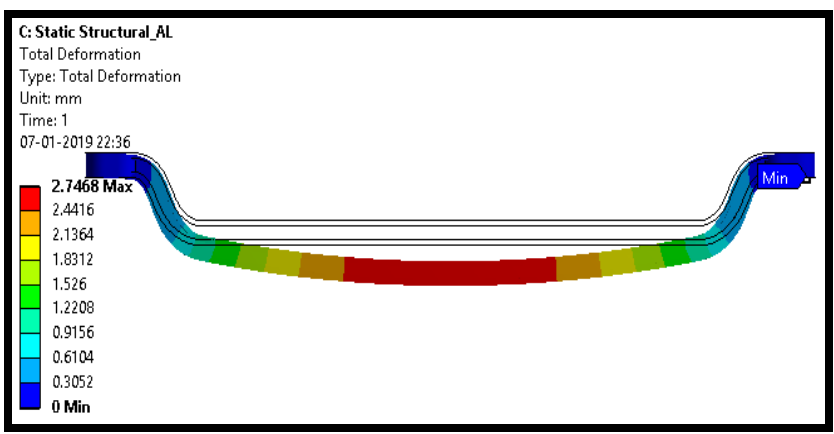

Fig:8 AL Alloy Deformations

When we check the Deformation of the Al Alloy under the loading condition at that time it structural steel deformed by $2.7468 \mathrm{~mm}$.

Steel and AL Alloy are ductile material and von mises theory is application for those material, hence von mises stresses were plotted and compared with material yield strength.

\begin{tabular}{|c|c|c|c|}
\hline SR No & Material & Mass (KG) & \% Change wrt Steel \\
\hline 1 & Steel & 58.294 & NA \\
\hline 2 & CI & 53.468 & $-8 \%$ \\
\hline 3 & AL Alloy & 20.57 & $-65 \%$ \\
\hline
\end{tabular}

Table No 3: Material density and volume, mass of front axle

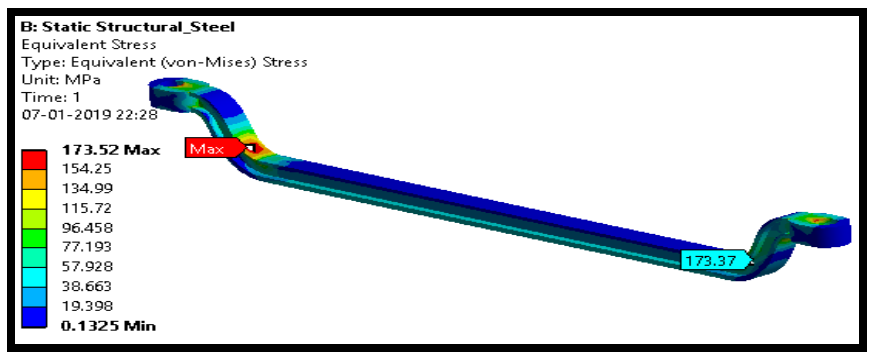

When we go for Von mises stress plot of structural steel, after the application of force $173.52 \mathrm{Mpa}$ stress is occurred at the red zone

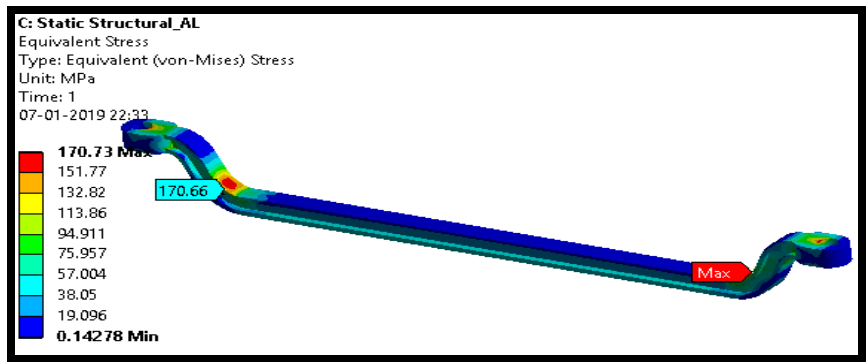

Fig 10: Von Mises Stress Plot of AL Alloy

When we go for Von mises stress plot of $\mathrm{Al}$ alloy, after the application of force $170.73 \mathrm{Mpa}$ stress is occurred at the red zone

$\mathrm{CI}$ is brittle material and Max/Min Principal Stress theory is applicable for such material and hence Max. /Min. principal Stresses were plotted and compared with UTS/UCS of material.

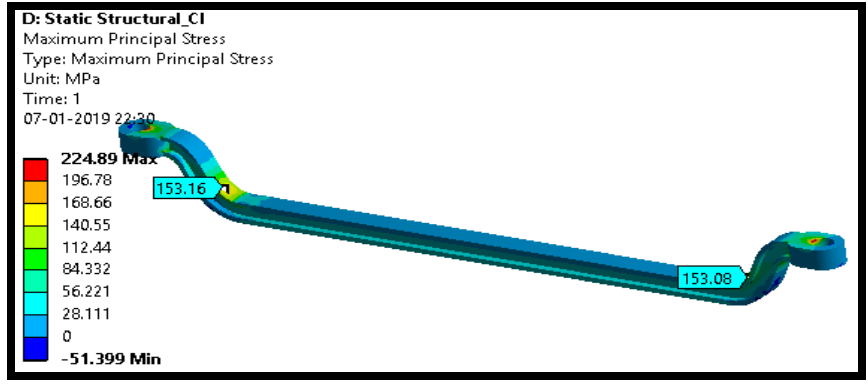

Fig No 11.Maximum principal stress plot.

When we go for Maximum minimum principal stress theory plot of Gray cast iron, after the application of force, $224.89 \mathrm{Mpa}$ stress is occurred at the red zone

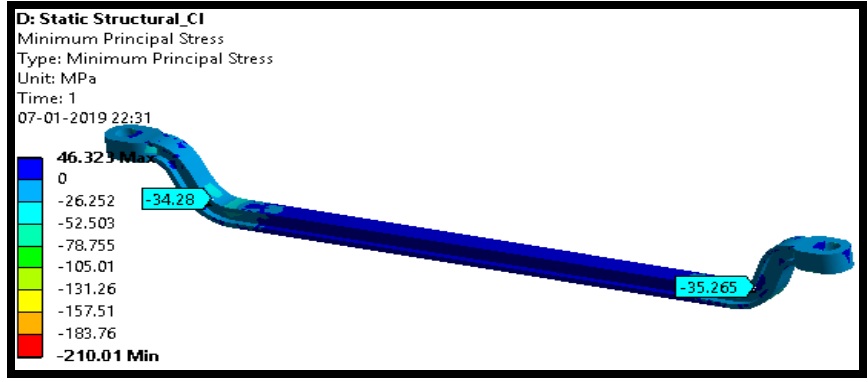

Fig No 12.Minimum principal stress plot. 
When we go for minimum principal stress theory plot of

Gray cast iron, after the application of force, 46.32Mpa

\begin{tabular}{|l|c|c|c|c|l|}
\hline $\begin{array}{c}\text { Sr } \\
\text { No }\end{array}$ & Material & $\begin{array}{c}\text { Deformation } \\
(\mathbf{m m})\end{array}$ & $\begin{array}{c}\text { Stresses } \\
(\mathbf{M P a})\end{array}$ & $\begin{array}{c}\text { Material } \\
\text { Limit }\end{array}$ & FOS \\
\hline 1 & Steel & 1.007 & 173.52 & 250 & 1.44 \\
\hline 2 & CI & 1.8016 & 153.16 & 240 & 1.57 \\
\hline 3 & $\begin{array}{c}\text { AL } \\
\text { Alloy }\end{array}$ & 2.7468 & 172.88 & 280 & 1.62 \\
\hline
\end{tabular}

Table No. 4 Static analysis results

\section{FATIGUE ANALYSIS OF AXLE}

Stress Life based on empirical S-N curves is considered here to calculate fatigue life of leaf spring. Constant amplitude with fully reverse loading were considered with Goodman theory for the mean stress.

\section{FATIGUE RESULTS:}

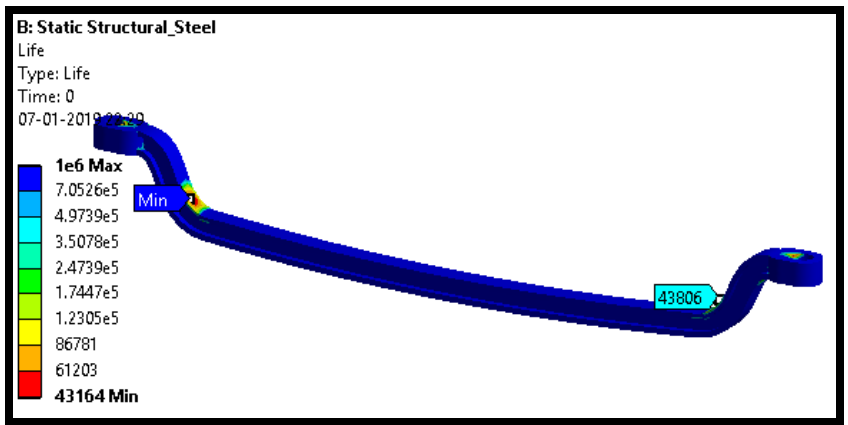

Fig:13 Life plot of Steel Axle

When we are calculating the life cycle of the structural steel material, the minimum number of cycle for structural steel is 43163

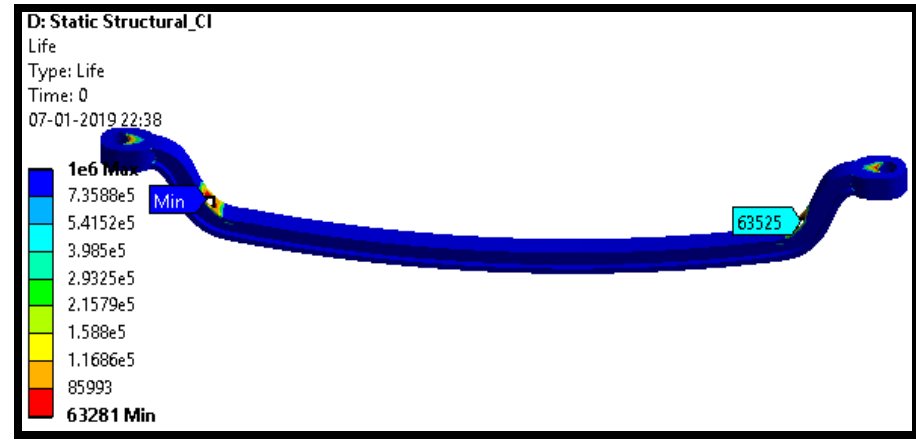

Fig:14 Life plot of CI Axle

When we are calculating the life cycle of the Gray cast iron material, the minimum number of cycle for gray cast iron is 63281.

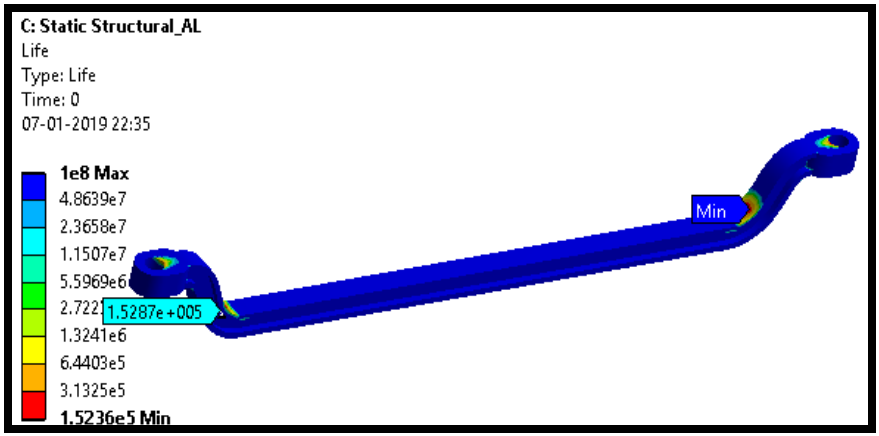

Fig:15 Life plot of AL Alloy Axle

When we are calculating the life cycle of the Al Alloy material, the minimum number of cycle for Al Alloy is $1.52 \mathrm{E}+05$

\begin{tabular}{|c|c|c|c|}
\hline SR No & Material & Life (Cycles) & $\%$ Change wrt Steel \\
\hline 1 & Steel & 43163 & NA \\
\hline 2 & CI & 63281 & $47 \%$ \\
\hline 3 & AL Alloy & $1.52 \mathrm{E}+05$ & $253 \%$ \\
\hline
\end{tabular}

Table No 5: Fatigue Results

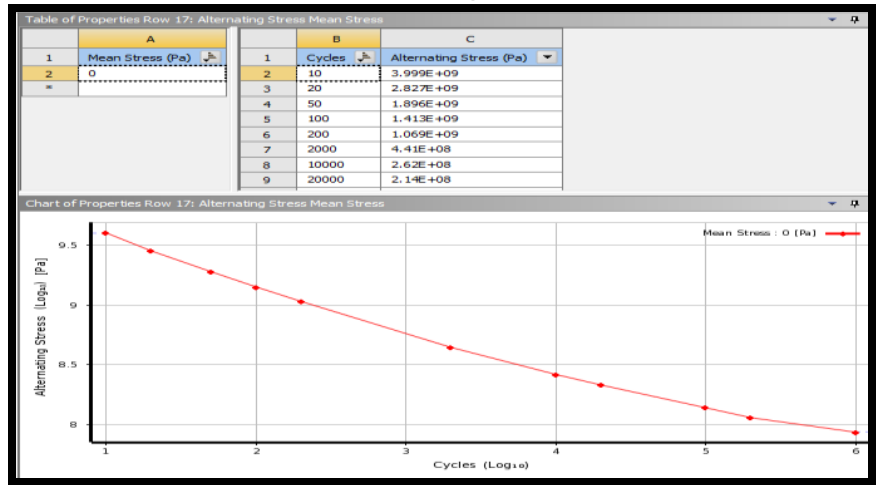

Fig: 16 S-N Curve for Steel/CI material

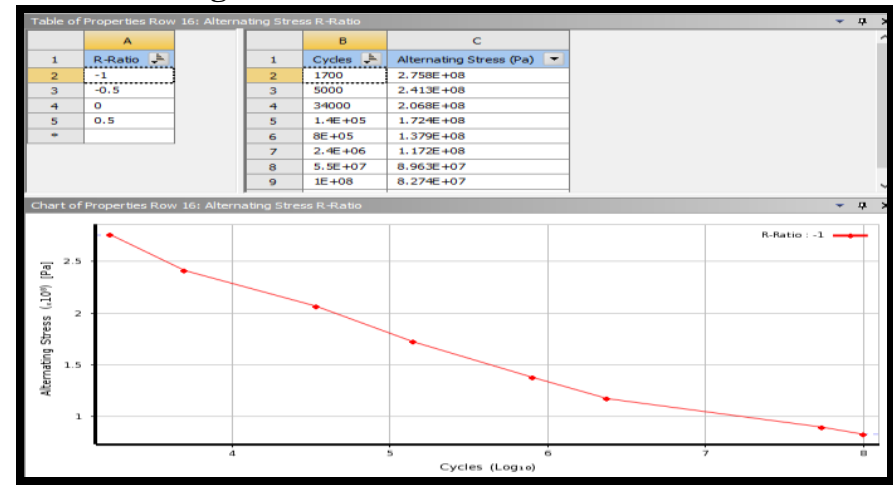

Fig: 17 S-N Curve for AL material 


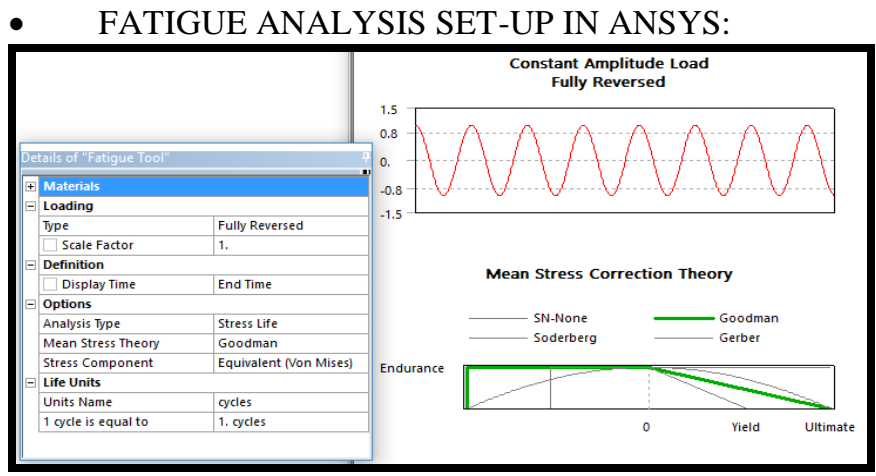

Fig:18 Fully Reverse Loading used for fatigue

\section{OPTIMIZATION RESULTS:}

Based on FEA results, we proposed material for cost and mass optimization is AL Alloy because of below reasons;

- Having highest factor of safety of 1.62 which is $11 \%$ higher than that of steel.

- Fatigue life is improved by $250 \%$ than that of steel life.

- Natural frequency also seen highest among all material and does not occur resonance condition.

- $\quad \mathrm{AL}$ Alloy has axle weight of $21 \mathrm{Kg}$ which is $65 \%$ lesser than that of existing material steel of $58 \mathrm{Kg}$.

- $50 \%$ reduction in material cost observed with $\mathrm{AL}$ Alloy.

\begin{tabular}{|c|c|c|c|c|c|}
\hline SR No & Material & Deformation(mm) & Stresses(MPa) & $\begin{array}{c}\text { Material } \\
\text { Limit }\end{array}$ & FOS \\
\hline 1 & Steel & 1.007 & 173.52 & 250 & 1.44 \\
\hline 2 & CI & 1.8016 & 153.16 & 240 & 1.57 \\
\hline 3 & AL Alloy & 2.7468 & 172.88 & 280 & 1.62 \\
\hline
\end{tabular}

\begin{tabular}{|c|c|c|c|}
\hline $\begin{array}{c}\text { SR } \\
\text { No }\end{array}$ & Material & Mass (KG) & $\begin{array}{c}\% \text { Change wrt } \\
\text { Steel }\end{array}$ \\
\hline 1 & Steel & 58.294 & NA \\
\hline 2 & CI & 53.468 & $-8 \%$ \\
\hline 3 & AL Alloy & 20.57 & $-65 \%$ \\
\hline
\end{tabular}

Steel per $\mathrm{Kg}$ Cost $=200 \mathrm{Rs}$

AL Alloy per Kg Cost=250RS

Total material cost Steel: $200 * 58=11600 \mathrm{Rs}$

Total material cost AL Alloy: 250*21 = 5250Rs

Other cost as below $=$

Pattern Cost: 4000Rs

Casting Cost $=3500 \mathrm{RS}$

Machining Cost $=2500 \mathrm{RS}$.

Total Cost excluding material cost is 10000Rs which will remain same for all material.

VIII. PHYSICAL MODEL WORK
A based FEA result, AL alloy material was proposed and hence physical model of AL alloy mentioned below was considered

to prepare.

\begin{tabular}{|c|c|c|c|c|c|c|}
\hline $\begin{array}{c}\text { Al Ass. } \\
\text { No }\end{array}$ & $\begin{array}{c}\text { Composition } \\
\text { (wt.\%) }\end{array}$ & Condition & $\begin{array}{c}\mathbf{Y S} \\
(\mathbf{M P a})\end{array}$ & $\begin{array}{c}\text { UTS } \\
(\mathrm{MPa})\end{array}$ & $\%$ EI & Applications \\
\hline 1100 & $0.12 \mathrm{Cu}$ & $\begin{array}{l}\text { Annealed } \\
\text { (O) }\end{array}$ & 35 & 90 & 45 & $\begin{array}{l}\text { Food/chemical handling } \\
\text { equipment, heat exchangers } \\
\text { light reflectors }\end{array}$ \\
\hline 3003 & $\begin{array}{l}0.12 \mathrm{Cu}, 1.2 \\
\mathrm{Mn}, 0.1 \mathrm{Zn}\end{array}$ & Annealed & 40 & 110 & 30 & $\begin{array}{l}\text { Utensils, pressure vessels and } \\
\text { piping }\end{array}$ \\
\hline 5052 & $\begin{array}{l}2.5 \mathrm{Mg}, 0.25 \\
\mathrm{Cr}\end{array}$ & $\begin{array}{l}\text { Strain-hardn. } \\
\quad(\mathrm{H} 32)\end{array}$ & 195 & 230 & 14 & $\begin{array}{l}\text { Bellows, clutch disk, } \\
\text { diaphragm, fuse clips, springs }\end{array}$ \\
\hline 2024 & $\begin{array}{l}4.4 \mathrm{Cu}, 1.5 \\
\mathrm{Mg}, \quad 0.6 \mathrm{Mn}\end{array}$ & $\begin{array}{l}\text { Heat treated } \\
\quad(\mathrm{T} 4)\end{array}$ & 325 & 470 & 20 & $\begin{array}{l}\text { Aircraft structure, rivets, truck } \\
\text { wheels, screw }\end{array}$ \\
\hline
\end{tabular}

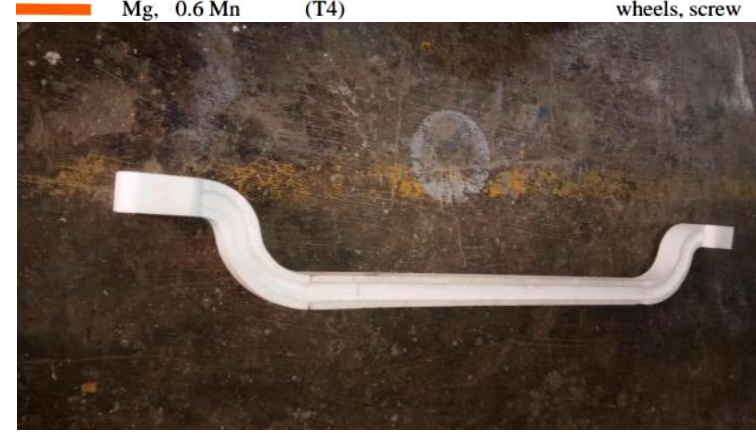

Fig19- Thermocol Pattern

CASTING PROCESS

Sand casting, the most widely used casting process, utilizes expendable sand moulds to form complex metal parts that can be made of nearly any alloy. Because the sand mould must be destroyed in order to remove the part, called the casting, sand casting typically has a low production rate. The sand casting process involves the use of a furnace, metal, pattern, and sand mould. The metal is melted in the furnace and then ladled and poured into the cavity of the sand mould, which is formed by the pattern.

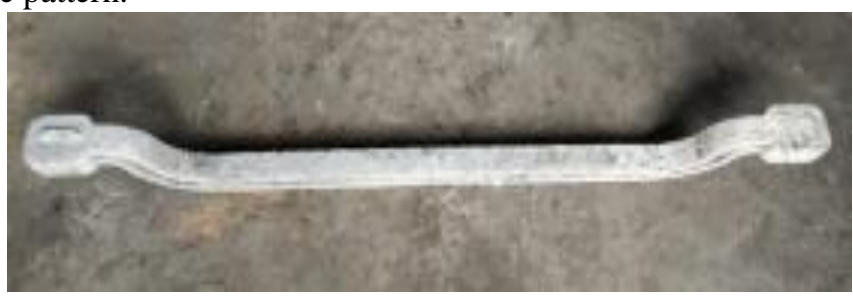

Fig20 : Al alloy Casting Part

\section{EXPERIMENTAL WORK}

Tensile testing, conjointly referred to as tension testing, may be a basic materials science and engineering check during which a sample is subjected to a controlled tension till failure. Properties that area unit directly measured via a tensile check area unit final enduringness, breaking strength, most elongation and reduction in space. From these measurements the subsequent properties can even be determined: modulus of elasticity, Poisson's quantitative relation, yield strength, and strain-hardening characteristics. Uniaxial tensile testing is that the most ordinarily used for getting the mechanical 
characteristics of isotropous materials. Some materials use line tensile testing. The most common testing machine employed in tensile testing is that the universal testing machine. this sort of machine has 2 crossheads; one is adjusted for the length of the specimen and also the different is driven to use tension to the check specimen. There area unit 2 types: hydraulic powerdriven and electromagnetically power-driven machines. The machine should have the correct capabilities for the check specimen being tested. There area unit four main parameters: force capability, speed, preciseness and accuracy. Force capability refers to the actual fact that the machine should be ready to generate enough force to fracture the specimen. The machine should be ready to apply the force quickly or slowly enough to properly mimic the particular application. Finally, the machine should be ready to accurately and exactly live the gauge length and forces applied; as an example, an outsized machine that's designed to live long elongations might not work with a brittle material that experiences short elongations before fracturing.

Alignment of the check specimen within the testing machine is essential, as a result of if the specimen is misaligned, either at associate degree angle or offset to 1 facet, the machine can exert a bending force on the specimen. this can be particularly unhealthy for brittle materials, as a result of it'll dramatically skew the results. this example are often decreased by victimization spherical seats or U-joints between the grips and also the check machine. If the initial portion of the stressstrain curve is sinuous and not linear, it indicates the specimen is misaligned within the testing machine.

The strain measurements area unit most ordinarily measured with associate degree extensometer, however strain gauges are ofttimes used on little check specimen or once Poisson's quantitative relation is being measured. Newer check machines have digital time, force, and elongation measuring systems consisting of electronic sensors connected to a knowledge assortment device (often a computer) and software system to govern and output the info. However, analog machines still meet and exceed ASTM, NIST, and ASM metal tensile testing accuracy needs, continued to be used these days.

\section{UNIVERSAL TESTING MACHINE:}

A universal testing machine (UTM), conjointly referred to as a universal tester, materials checking machine or materials test frame, is employed to check the enduringness and compressive strength of materials. associate degree earlier name for a tensile testing machine may be a tensometer. The "universal" a part of the name reflects that it will perform several customary tensile and compression tests on materials, components, and structures (in different words, that it's versatile).

\section{Components:}

Common parts include:

Load frame - sometimes consisting of 2 sturdy supports for the machine. Some little machines have one support.
Load cell - A force electrical device or different means that of mensuration the load is needed. Periodic standardization is sometimes needed by governing laws or quality system.

Cross head - A movable cross head (crosshead) is controlled to maneuver up or down. sometimes this can be at a continuing speed: generally referred to as a continuing rate of extension (CRE) machine. Some machines will program the crosshead speed or conduct alternating testing, testing at constant force, testing at constant deformation, etc. mechanical device, servo-hydraulic, linear drive, and resonance drive area unit used.

Means of mensuration extension or deformation - several checks need a live of the response of the test specimen to the movement of the cross head. Extensometers area unit generally used.

Output device - a method of providing the check result's required. Some older machines have dial or digital displays and chart recorders. many more recent machines have a laptop interface for analysis and printing.

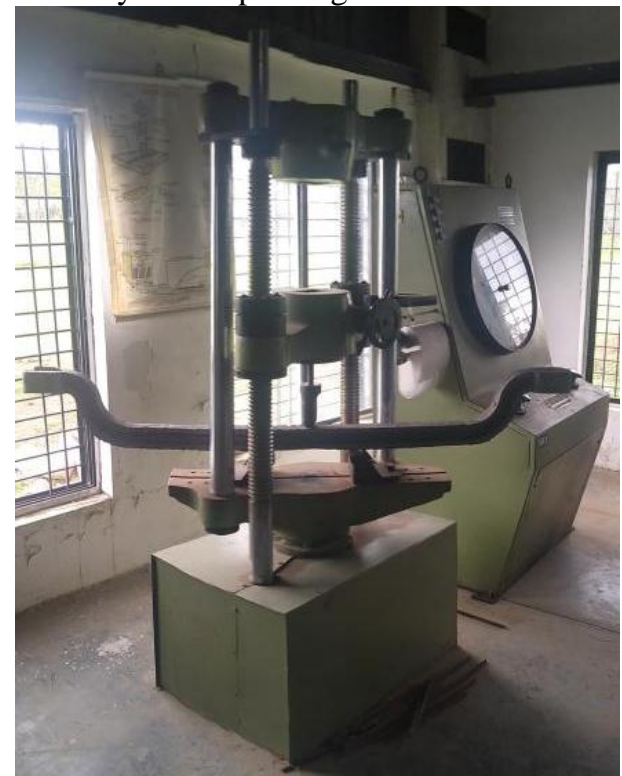

Fig21 : Testing on universal testing machine Experimental Testing

\begin{tabular}{|c|c|c|}
\hline \multirow{2}{*}{ Load(N) } & EXPERIMENTAL & FEA \\
\cline { 2 - 3 } & \multicolumn{2}{|c|}{ Deflection(mm) } \\
\hline 17569 & 0.288 & 0.308 \\
\hline 35138 & 0.573 & 0.603 \\
\hline 52707 & 0.855 & 0.905 \\
\hline 70276 & 1.133 & 1.183 \\
\hline 87845 & 1.409 & 1.459 \\
\hline $1.05 \mathrm{E}+05$ & 1.682 & 1.732 \\
\hline $1.23 \mathrm{E}+05$ & 1.952 & 2.002 \\
\hline $1.41 \mathrm{E}+05$ & 2.219 & 2.279 \\
\hline $1.58 \mathrm{E}+05$ & 2.484 & 2.554 \\
\hline $1.76 \mathrm{E}+05$ & 2.746 & 2.826 \\
\hline
\end{tabular}


Table5 :- Comparison of Experimental and FEA results

\begin{tabular}{|c|c|c|c|}
\hline Front Axle & $\begin{array}{c}\text { Experimental } \\
\text { Results }\end{array}$ & $\begin{array}{c}\text { ANSYS } \\
\text { Results }\end{array}$ & $\begin{array}{c}\text { Percentage } \\
\text { Difference }\end{array}$ \\
\hline $\begin{array}{c}\text { Static } \\
\text { Deformation(mm) }\end{array}$ & 2.746 & 2.826 & $3 \%$ \\
\hline
\end{tabular}

Table 6 :- Percentage change of deformation between Experimetal \& FEA results

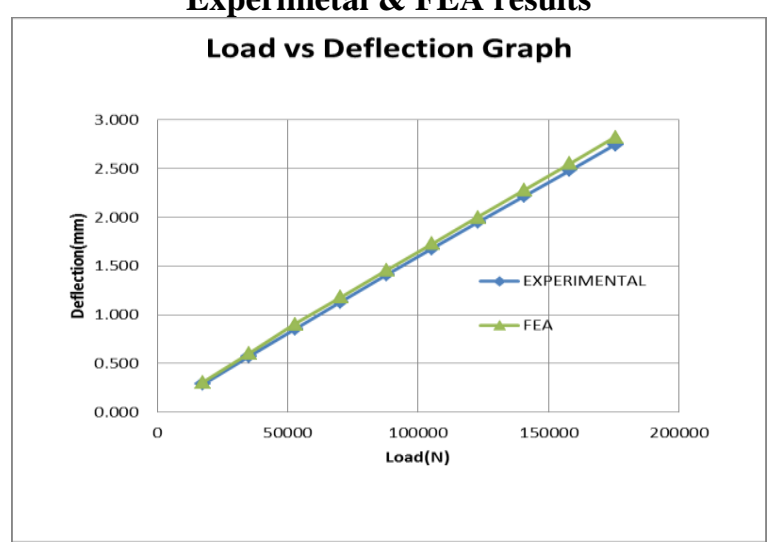

Fig22: Combine Load vs Deflection graph

Load deflection curev calculated in FEA and experimental has obbsrved 3-4 \% variation. The results are validated and hence we can conclude that the ANSYS results are reliable and can be applied for complicated analysis.

\section{CONCLUSIONS}

Front Axle design of light truck application has been studied for different materials. Stresses of all materials are less than material yield and ultimate tensile/compressive strength and hence it is material are meeting static analysis acceptance limit. Axle with steel, CI and AL Alloy material have FOS safety of $1.44,1.57$ and 1.62 respectively. Axle life of steel is observed to be least \& AL Alloy observed life of axle highest among all material. CI gives 1st natural frequency very close to excitation frequency and there are high chances of resonance condition to be occurring and cause catastrophically failure of axle and hence CI material is not recommended for this axle. First natural frequency of all Steel and AL Alloy material is higher than excitation frequency and hence the resonance conditions will never going to achieve. Based on FEA results, we proposed material for cost and mass optimization is AL Alloy because of below reasons;

1. Having highest factor of safety of 1.62 which is $11 \%$ higher than that of steel.

2. Fatigue life is improved by $250 \%$ than that of steel life.

3. Natural frequency also seen highest among all material and does not occur resonance condition.

4. AL Alloy has axle weight of $21 \mathrm{Kg}$ which is $65 \%$ lesser than that of existing material steel of $58 \mathrm{Kg}$.

\section{REFERENCES}

[1]MinZhang, XiangfeiJi, LijunLi, "fatigue life of front axle beam for heavy-duty truck", Sciencedirect Advances in Engineering Software, vol .91 pp.63-68, 2016.

[2]Zhen Li, Muneshi Mitsuoka, Eiji Inoue, Takashi Okayasu, Yasumaru Hirai,"Development of stability indicators for dynamic Phase I overturn of conventional farm tractors with front axle pivot," in Sciencedirect b i o s y s t ems engineering , vol.134, pp. 55-67, 2015.

[3] Ketan Vijay Dhande, Prashant Ulhe ， "Design and analysis of front axle of Heavy commercial vehicle," in International Journal of Science, Technology \& Management Vol.03, ISSN (online): 2394-1537, Issue No. 12, 2014.

[4] Pravin R.Ahire, Prof.K. H. Munde, "Design and analysis of front axle for heavy commercial vehicle," in International Journal Of Engineering And Computer Science, Vol 5, pp.17333-17337,2016.

[5] K.Padma Raju, B.Jithendra Kumar, "Design and Analysis of a Heavy Vehicle Front Axle," in International Journal \& magazine of engineering technology \& management \& research, vol 4, pp 263-268, 2017.

[6]S. Eswaran ,B.Dinakaran ,L.Jeevankumar ,K.P.Karthick , S.Karthick, "Design And Structural Analysis Of Heavy Duty Vehicle Fornt Axle," in International Journal of Science and Engineering Research (IJOSER), Vol 4, pp. 5687-5690, 2016.

[7] M.Porus Purushothaman, V Jayachandran, "Finite element analysis of front Axle frame of heavy duty truck With CI material model." In IJERTET, vol.6, pp 476-469,2013. 